\title{
Comparison of the Effects of T-1815, Yohimbine and Naloxone on Mouse Colonic Propulsion
}

\author{
Kenji YAMADA and Yuichi ONODA \\ Pharmacological Research Laboratory, Tanabe Seiyaku Co., Ltd., 2-2-50, \\ Kawagishi, Toda, Saitama 335, Japan
}

\begin{abstract}
The colonic prokinetic activity of a newly synthesized compound, T-1815, administered orally, was compared with that of yohimbine and naloxone in mice. The time required to evacuate a glass bead inserted into the distal colon was taken as an index of prokinetic activity. Clonidine (3-30 $\mu \mathrm{g} / \mathrm{kg}$ s.c.), and loperamide $(0.3-3.0 \mathrm{mg} / \mathrm{kg}$ s.c.) delayed bead expulsion in a dose-dependent manner. Yohimbine $(0.3-10 \mathrm{mg} / \mathrm{kg})$ and T-1815 $(0.1-10 \mathrm{mg} /$ $\mathrm{kg}$ ) showed a dose-dependent reduction of the delay in evacuation induced by clonidine, but naloxone had no effect. The loperamide-induced retardation of colonic propulsion was reduced by naloxone $(0.3-10 \mathrm{mg} / \mathrm{kg})$ and $\mathrm{T}-1815(0.1-10 \mathrm{mg} / \mathrm{kg})$ in a dose-dependent manner, but yohimbine had no effect. In normal animals, yohimbine and naloxone had no significant effect on evacuation, while a slight acceleration was observed with T-1815 at $10 \mathrm{mg} / \mathrm{kg}$. No soft feces and/or diarrhea were observed with any of the three test drugs. These results indicate that $\mathrm{T}-1815$ appears to be a unique colonic prokinetic compound, the action of which may be mediated through mechanisms other than antagonism for $\alpha_{2}$-adrenoceptors or opioid receptors.
\end{abstract}

Key words: mice: colon transit; constipation; yohimbine; naloxone; T-1815 (a thienylalkylamine derivative)

\section{Introduction}

It has been reported that not a few persons complain of constipation; for example, $10 \%$ of a healthy population in Britain (Kamm, 1991), and $8.0 \%$ of men and $20.8 \%$ of women in the United States (Everhart et al., 1989) do so. Laxatives are widely used in the treatment of constipation, but they have undesirable properties, such as the induction of diarrhea, potential for abuse, and/or the development of tolerance (Brunton, 1985). Medications, other than presently available laxatives, to relieve constipation would thus be valuable.

It has been shown that colonic propulsive activity can be evaluated by measuring the time taken to evacuate a small bead inserted into the colon of mice and rats (Schottek, 1967 ; Jacoby and Lopez, 1984 ; Pendleton $e t$ al., 1986). Evacuation is delayed by the adrenergic $\alpha_{2}$-receptor agonist, clonidine, and by some opioid agonists (Jacoby and Lopez, 1984 ; Pendleton et al., 1986). Animals with a drug-induced delay in propulsion are considered to be constipation models.

By screening numerous compounds, using the above-mentioned animal models for constipa- 


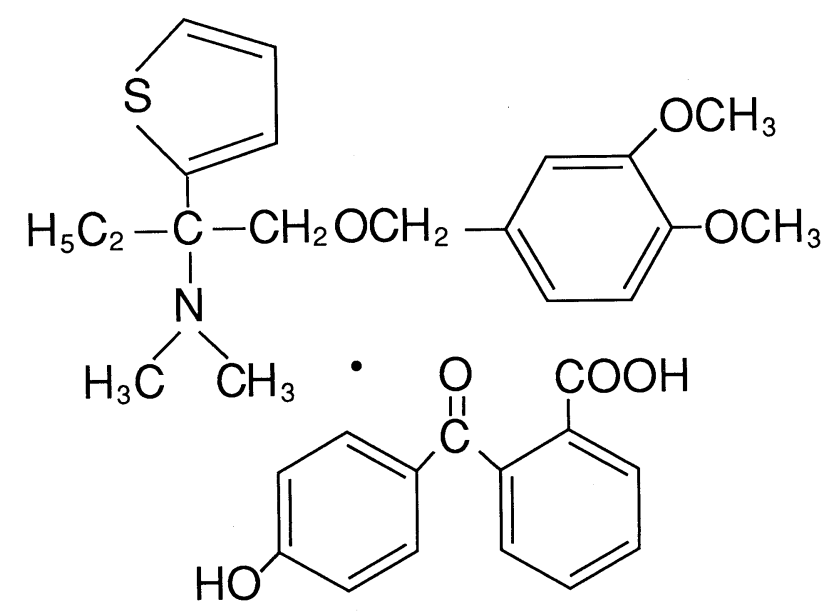

Fig. 1. Chemical structure of T-1815.

tion, we found a compound, designated T-1815 [( \pm )-1-[(3, 4-dimethoxybenzyl) oxymethyl $]-1-$ (2-thienyl)-N, N-dimethyl-n-propylamine 2-(4-hydroxybenzoyl)-benzoate; Fig. 1], that markedly improved delayed colonic propulsion in mice. In the present study, we carried out additional experiments with the compound to compare its effects with those of an adrenergic $\alpha_{2}$-receptor antagonist, yohimbine, and an opioid receptor antagonist, naloxone.

\section{Materials and Methods}

Four-week-old male Slc: ddY mice, weighing $22-28$ g, were used.

Experiments were done according basically to the method of Pendleton et al. (1986). Animals were fasted for 4 hours and then a glass bead ( $3 \mathrm{~mm}$ in diameter) was inserted into the distal colon $3 \mathrm{~cm}$ above the anus. The time required to evacuate the bead was measured and used as an index of colonic propulsive activity.

First, the dose-response relationships of the inhibitory effects of subcutaneous clonidine and loperamide on colonic propulsion were examined by giving the drugs $20 \mathrm{~min}$ before bead insertion.

Second, the effects of the three test compounds (yohimbine, naloxone, and T-1815) on colonic propulsion were compared in three groups of mice: 1) clonidine-treated, 2) loperamide-treated, and 3) normal (naive) mice. In normal (naive) animals, the stool output was observed and we determined if its form was normal, soft, or diarrheal. Each test compound was administered orally $30 \mathrm{~min}$ before bead insertion (10 min before clonidine or loperamide).

The drugs used were clonidine (Tokyo Kasei), loperamide (Sigma), yohimbine hydrochloride (Nacalai Tesque), naloxone hydrochloride (Sigma), and T-1815 (synthesized by Tanabe Seiyaku). Clonidine was dissolved in, and loperamide was suspended in physiological saline ; they were administered subcutaneously at a volume of $10 \mathrm{ml} / \mathrm{kg}$. Yohimbine, naloxone, and $\mathrm{T}-1815$ were dissolved in distilled water and given orally at $10 \mathrm{ml} / \mathrm{kg}$.

Statistical analysis was performed using the analysis of variance (ANOVA) method. 


\section{Results}

\subsection{Inhibitory effects of clonidine and loperamide on mouse colonic propulsion}

Clonidine delayed bead evacuation dose-dependently at doses of 3-30 $\mu \mathrm{g} / \mathrm{kg}$ s.c. (Fig. 2-A). The average evacuation time at $10 \mu \mathrm{g} / \mathrm{kg}$ was about 5 times longer than that in the control group.

Loperamide, at $0.3-3.0 \mathrm{mg} / \mathrm{kg}$ s.c., also produced a dose-dependent delay of bead expulsion (Fig. 2-B). The evacuation time at $1.0 \mathrm{mg} / \mathrm{kg}$ was approximately 5 times longer than that in control animals.

3.2. Effects of yohimbine, naloxone, and T-1815 on the clonidine-induced delay of colonic propulsion

Figure 3 shows the effects of the three test drugs on the delay of bead evacuation induced by clonidine $(10 \mu \mathrm{g} / \mathrm{kg}$ s.c.). $\mathrm{T}-1815(0.1-10 \mathrm{mg} / \mathrm{kg}$ p.o.) showed an improvement of colonic propulsion in a dose-dependent manner, the maximum effect being observed at $3-10 \mathrm{mg} / \mathrm{kg}$. Yohimbine (0.3-10 $\mathrm{mg} / \mathrm{kg}$ p.o.) also reduced the delay in expulsion, although naloxone (1 and 10 $\mathrm{mg} / \mathrm{kg}$ p.o.) failed to do so.
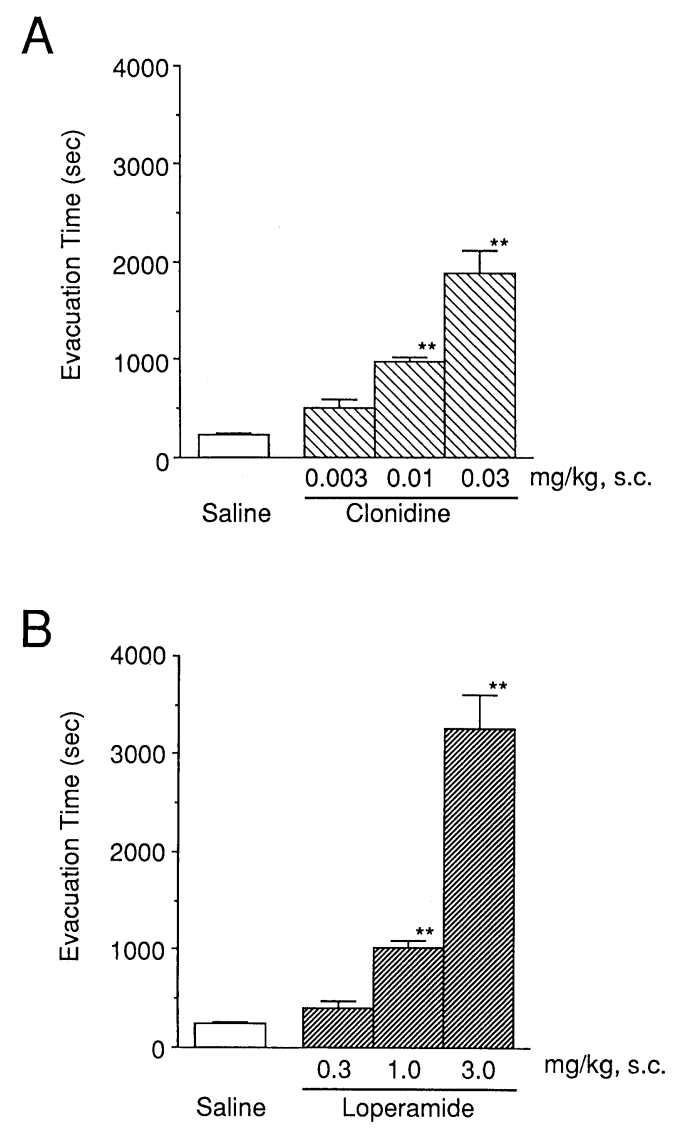

Fig. 2. Effects of subcutaneous clonidine (A) and loperamide $(\mathrm{B})$ on colonic propulsion in mice.

Ordinate: Time (sec) required to evacuate glass bead inserted into the colon 20 min after administration of clonidine or loperamide. Values are means \pm S.E. $\mathrm{N}=10$ (A) and 20 (B). ${ }^{*},{ }^{* *} \mathrm{p}<0.05,0.01$ vs saline. 


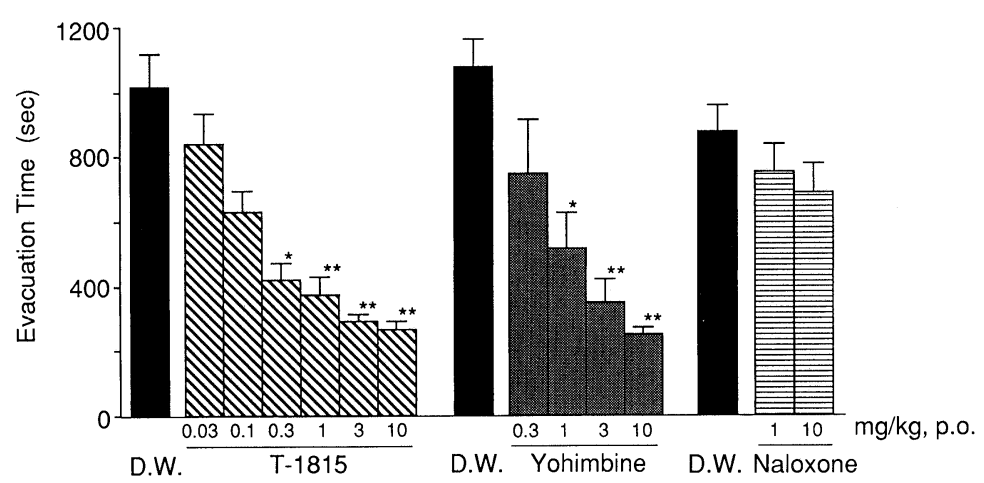

Fig. 3. Effects of oral T-1815, yohimbine, and naloxone on clonidine-induced delay of colonic propulsion in mice.

Ordinate: Time $(\mathrm{sec})$ required to evacuate the bead. Values are means \pm S.E. $N=10$. D.W. : distilled water. ${ }^{*},{ }^{* *} \mathrm{p}<0.05,0.01$ vs (clonidine + D.W.)

3.3. Effects of yohimbine, naloxone, and $T-1815$ on the loperamide-induced delay of colonic propulsion

Naloxone $(0.3-10 \mathrm{mg} / \mathrm{kg}$ p.o.) reduced the delay in propulsion induced by loperamide $(1.0$ $\mathrm{mg} / \mathrm{kg}$ s.c.), while yohimbine ( 1 and $10 \mathrm{mg} / \mathrm{kg}$ p.o.) did not affect the delay (Fig. 4). T-1815 (0.1-10 mg/kg p.o.) produced a dose-dependent reversal of the loperamide-induced delay of colonic propulsion.

\subsection{Effects of yohimbine, naloxone, and $T-1815$ on colonic propulsion in normal mice}

Oral administration of both yohimbine and naloxone, at doses of 1 and $10 \mathrm{mg} / \mathrm{kg}$ for both drugs, did not have any influence on bead evacuation in naive mice (Fig. 5). However, T-1815 $(10 \mathrm{mg} / \mathrm{kg}$ p.o.) produced a significant acceleration of bead expulsion. Neither soft feces nor diarrhea was observed after administration of any of the three test drugs.

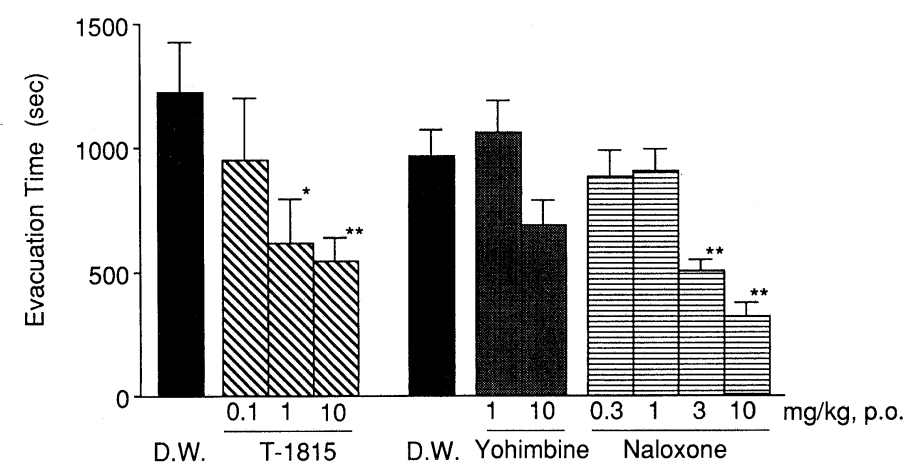

Fig. 4. Effects of oral T-1815, yohimbine, and naloxone on loperamide-induced delay of colonic propulsion in mice.

Ordinate: Time $(\mathrm{sec})$ required to evacuate the bead. Values are means \pm S.E. $N=10$.

D.W. : distilled water. ${ }^{*},{ }^{* *} \mathrm{p}<0.05,0.01$ vs (loperamide + D.W.) 


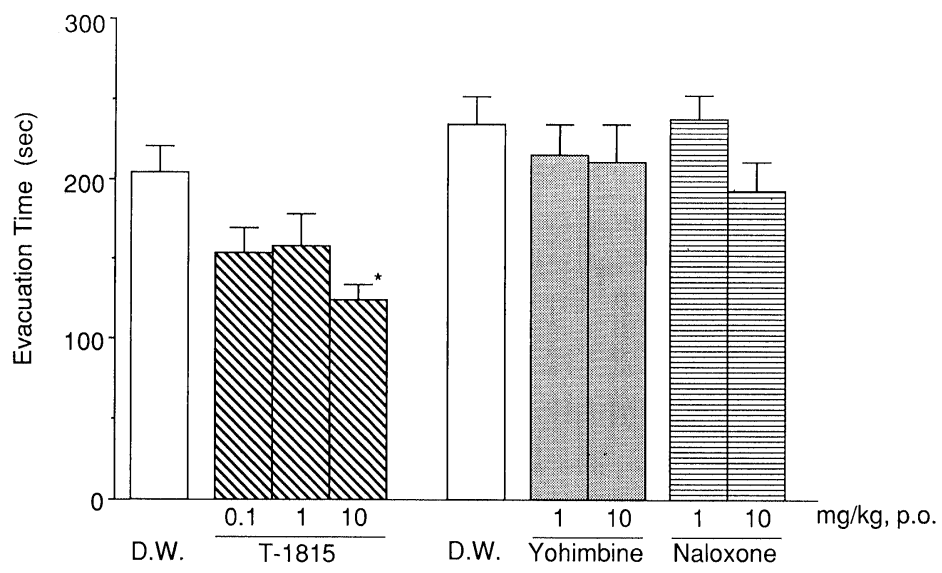

Fig. 5. Effects of oral T-1815, yohimbine, and naloxone on bead evacuation in normal mice. Ordinate: Time $(\mathrm{sec})$ required to evacuate the bead. Values are means \pm S.E. $\mathrm{N}=10$. D.W. : distilled water. ${ }^{*} \mathrm{p}<0.05$ vs D.W.

\section{Discussion}

In the present experiments, colonic propulsive activity was measured as the time required for the evacuation of a bead inserted into the colon in mice. Subcutaneous administration of an $\alpha_{2}$-adrenoceptor agonist, clonidine, and an opioid agonist, loperamide, caused a dosedependent delay of bead evacuation; the results obtained agreed qualitatively with those of Jacoby and Lopez (1984) and those of Pendleton et al. (1986).

It has been reported that clonidine has a potent antidiarrheal effect in mice (Doherty and Hancock, 1983) and rats (Thollander et al., 1989), and that this compound also has a suppressive effect on small intestinal motility both in vivo (Thollander et al., 1989 ; Hallerback et al., 1987) and in vitro (Doherty and Hancock, 1983). It can, therefore, be considered that the clonidineinduced delay of colonic propulsion is a model of atonic constipation. Loperamide is a synthetic opioid agonist and antidiarrheal agent that, in humans, prolongs the oro-cecal transit time and reduces stool frequency (Becker et al., 1989), and causes constipation (Kachel et al., 1986). Intravenous loperamide produces an increase in tone in the guinea pig colon, with an inhibition of peristalsis (Sohji et al., 1978), and the compound administered orally stimulates gastrointestinal motility in dogs (Fioramonti et al., 1987). Accordingly, the delay of colonic propulsion induced by loperamide is regarded as a model of spastic constipation.

The inhibitory effects of clonidine on small and large intestinal motility are due to its action via peripheral $\alpha_{2}$-receptors (Thollander et al., 1989). The tonic inhibition of colonic motility is also mediated by $\alpha_{2}$-adrenergic receptors in the peripheral nervous system (Doherty and Hancock, 1983 ; Gillis et al., 1987). The site of action of loperamide is also considered to be peripheral, since intracerebroventricular administration of loperamide induces the opposite effect, i.e., inhibition of gastrointestinal motility (Fioramonti et al., 1987). It is, therefore, likely that the site of action for the two constipation models is peripheral.

Yohimbine, a selective $\alpha_{2}$-antagonist, overcame the delay of bead expulsion induced by 
clonidine, while naloxone, a potent opioid antagonist, reversed the delay induced by loperamide, as was expected. However, the $\alpha_{2}$-antagonist had no effect on opioid agonist-induced delay and the opioid antagonist produced no improvement of $\alpha_{2}$-agonist-induced delay. In contrast, $\mathrm{T}-1815$ produced a dose-dependent improvement in both constipation models. These results suggest that T-1815 is an antagonist of both $\alpha_{2}$ - and opioid receptors and/or additional mechanism is involved in the action of this compound.

T-1815, at high doses, i.e., 100 and $300 \mathrm{mg} / \mathrm{kg}$ p.o., has negligible influence on the central nervous system in mice (Matsuoka, personal communication), while marked contractile responses to the compound have been observed in isolated circular smooth muscle of rat colon (unpublished data). These observations indicate the possibility that the site of action of T-1815 is peripheral.

Since no diarrhea and/or soft wet feces were observed in mice after oral administration of $\mathrm{T}-1815$, at the high dose of $10 \mathrm{mg} / \mathrm{kg}$, it is suggested that $\mathrm{T}-1815$ exerts its major effect on the motility of the colon and not on secretion. In the dog colon, T-1815 elicits high-amplitude (giant) contractions (manuscript in preparation), which are closely related to defecation (Karaus and Sarna, 1987). T-1815 can therefore be regarded as a colonic prokinetic compound.

In addition, although $\mathrm{T}-1815$ showed potent accelerating effects in the two constipation models, it had only a weak effect on normal (naive) animals. Although the mechanism of action of T-1815 remains to be investigated, it would appear that this property is desirable for an anti-constipation agent.

\section{Acknowledgements}

We thank Miss Keiko Shimada for her skilful technical and artistic assistance.

\section{References}

Becker, J.M., Dunnegan, D.L., Meinenger, T.A. and Soper, N.J. (1989). Loperamide improves functional results following ileal pouch-anal anastomosis. Gastroenterology 96: A36.

Brunton, L.L. (1985). Laxatives, In: The Pharmacological Basis of Therapeutics, ed. by A.G. Gilman, L.S. Goodman, T.W. Rall and F. Murad, MacMillan, New York, pp. 994-1003.

Doherty, N.S. and Hancock, A.A. (1983). Role of $\alpha_{2}$ adrenergic receptors in the control of diarrhea and intestinal motility. J. Pharmacol. Exp. Ther. 225: 269-274.

Everhart, J.E., Go, V.L.W., Johannes, R.S., Fitzsimmons, S.C., Roth, H.P. and White, L.R. (1989). A longitudinal survey of self-reported bowel habits in the United States. Dig. Dis. Sci. 34: 1153-1162.

Fioramonti, J., Fargeas, M. and Bueno, L. (1987). Stimulation of gastrointestinal motility by loperamide in dogs. Dig. Dis. Sci. 32: 641-646.

Gillis, R.A., Souza, J.D., Hicks, K.A., Mangel, A.W., Pagani, F.D., Hamilton, B.L., Garvey III, T.Q., Pace, D.G., Browne, R.K. and Norman, W.P. (1987). Inhibitory control of proximal colonic motility by the sympathetic nervous system. Am. J. Physiol. 253: G531-G539.

Hallerback, B., Glise, H. and Sjoqvist, A. (1987). Reflex sympathetic inhibition of colonic motility in the cat. Scand. J. Gastroenterol. 22 : 141-148.

Jacoby, H.I. and Lopez, I. (1984). A method for the evaluation of colonic propulsive motility in the mouse after icv administered compounds. Dig. Dis. Sci. 29 : 551.

Kachel, G.,, Ruppin, H., Hagel, J., Barina, W., Meinhardt, M. and Domschke, W. (1986). Human 
intestinal motor activity and transport: effects of a synthetic opiate. Gastroenterology $\mathbf{9 0}$ : 85-93.

Kamm, M.A. (1991). Pathophysiology of constipation. In : The large intestine: Physiology, pathophysiology, and disease, ed. by S.F. Phillips and R.G. Shorter, Raven Press, New York, pp. 709-726.

Karaus, M. and Sarna, S.K. (1987). Giant migrating contractions during defecation in the dog colon. Gastroenterology 92 : 925-933.

Pendleton, R.G., Bendesky, R. and Cook, P.G. (1986). Effects of $\alpha_{2}$-adrenoceptor agonists upon colonic propulsion. Drug Develop. Res. 9 : 241-247.

Schottek, W. (1967). The "glass ball test"-an informing method for testing the influence of pharmaca on the peristalsis of the colon of rats. Arzneim. Forsch. 17:649-650.

Sohji, Y., Kawashima, K. and Shimizu, M. (1978). Pharmacological studies of loperamide, an antidiarreal agent. II. Effects on peristalsis of the small intestine and colon in guinea pigs. Folia Pharmacol. Japon. 74: 155-163.

Thollander, M., Hellstrom, P.M. and Svensson, T.H. (1989). Suppression of small intestinal motility and morphine withdrawal diarrhea by clonidine: peripheral site of action. Acta Physiol. Scand. 137 : 385-392. 